cian need know little of children's diseases. The/communication with his fellows; and yet man is the pediatrist must not only know adult medicine but very source of his own undoing. The original man special child-medicine as well.

What must be our aim, then, as physicians interested in this great branch of medical science? To so study it, practice it, write of it, teach it, work for it, that we may fit ourselves and others to aid in the best way the most helpless and defenceless, the most attractive, the most appealing of our patients-the children.

In closing I must express my indebtedness for valuable information obtained from the article by Rauchfuss on "Die Kinderheilanstalten," and that by Hennig on "Die Geschichte der Kinderkrankheiten," both in Gerhart's Handbuch der Kinderkrankheiten, Vol. i; that by Jacobi in the Introduction to the Cyclopedia of the Diseases of Children; that by Adams, on the "Evolution of Pediatric Literature in the United States," in the Archives of Peliatrics, June, 1897, and that by Kelley on "Pediatrics, Past, Present and Future," in the Cleveland Medical Gazette, September, 1896. Meissner's “Grundlage der Literatur der Pädiatrik"; an editorial in Pediatrics, Jan. 15, 1897; the Index Catalogue of the Library of the Surgeon-General's Office; Polk's Medical and Surgical Register of the United States; the Medical Directory for England, and the Bibliographical supplement of the Cyclopedia of Practical Medicine, by Forbes and his associates, have all been of service. I am also much indebted for information furnished in personal letters from Dr. Guinon of Paris, editor of the Revue Mensuelle des Maladies de l'Enfance; Dr. Frübwald of Vienna, editor of the Archives fuir Kinderheilkunde. Dr. Baginski and Dr. Heubner of Berlin, Dr. Saunders of St. Louis, Dr. Lambert of Indianapolis, Dr. Rotch of Boston, Dr. Adams of Washington, Dr. Booker of Baltimore and Drs. Brown, Adriance and Carr of New York. Last, and especially, I am indebted to Dr. Jacobi of New York for many useful suggestions and much valuable information given, both in personal letters and in conversation.

\title{
THE LIMITATIONS OF MEDICINE.
}

Address Delivered at the Opening Exercises of Rush Medieal College. September 27, 1898.

BY FRANK BILLINGS, M.D.

CHICAGO, ILL.

Medicine has for its object the relief of suffering and the prolongation of life. There exist many limitations to the successful accomplishment of this object. The limitations of medicine are less numerous today than in the past, and many of the obstacles to success in the prevention of disease and the healing of the sick will be removed in the future.

Medicine as a whole is not a science. Of some branches which enter into it our knowledge is exact; of others our information is theoretic, while every day adds to our knowledge and removes many obstacles from the path of progress. The chemic laboratory and the microscope have done much and will do more to make medicine a science. Progress in knowledge of chemistry and biology has been wonderful in the last twenty years, and this knowledge has removed many of the limitations of medicine. Strange as it may seem, the limitations of medicine which man is striving to remove, are due to man himself. was doubtless perfect in mind and body; the master of all created things. Like all organic life, his span was made up of periods of birth, growth, maturity and decay. He was doubtless able to combat his foes and sink at last, in the fulness of his years, in to euthanasiac sleep. The history of man, since the fall, is like the repeated pages of a book. Vicious habits mark his footsteps, whether civilized or barbarian; his habits of work and of rest, his food and drink, are not rational; he contaminates the air he breathes, the water he drinks and the food he eats. The water-sources and the earth, contaminated by man, become soil for the growth of the germs which infest and sicken him. His contaminated body begets a prototype, imperfect in mind and body. From the cradle to the grave a degenerate being, he fights against a mighty host, bred of his own shortcomings. Most of the infectious and contagious diseases may be classed as preventable; most of them are filth diseases, and they can not exist in the presence of perfect cleanliness.

A proper observation of hygienic rules relating to cleanliness of the person, of food, and of the watersupply, renders a population free of typhoid, cholera and other filth diseases. The example of the city of Vienna is sufficient to prove this. Previous to 1878 , Vienna received its water-supply from the Danube river, which was contaminated by the sewage of the city. While using this water-supply, Vienna suffered from the constant presence of typhoid fever, and cholera was a frequent visitor. The World's exposition of 1873 , at Vienna, was practically broken up because of a visitation of cholera and typhoid fever. In 1878 Vienna's new aqueduct was completed which brought pure water from the Semmering pass in the Carpathian Alps, a distance of seventy odd miles. From that time until the present, typhoid fever and cholera do not exist in Vienna, except as importations. There has been but one exception to this-which emphasizes the lesson of the value of pure water. I think it was in the year 1888 a break occurred in the Semmering aqueduct. The old watersupply was temporarily used, until the aqueduct was repaired. Typhoid fever again promptly appeared in the city, and continued until the pure water was again supplied.

Ideal sanitation would free the world of all diseases due to filth. What prevents ideal sanitation? Many things: jgnorance of the people, both rich and poor. educated and unread; an ignorance of what is real cleanliness of mind and body and of the drink and food they take. Health officers and family physicians terch in vain the value of cleanliness, the best methods of removing the contaminations of food and water, and the necessity of precautions in the presence of contagious diseases. Ignorance, prejudice and a love of dirt are often difficult to overcome. Sanitation has done much to overcome the evils of self-contamination of water, milk and other food. Sanitarians have not only the ignorance and prejudice of the people to overcome, but also the avarice of commerce. Air pollution by smoke and odors; sewage increase and consequent increased pollution from the byproducts of packing-houses, manufactories, etc., food adulteration to meet competition in trade, are condi-

Man is the highest type of animal, endowed with a tions not easily overcome, because of the political mind capable of reason, and gifted with a means of influence the dollar commands, especially in our 
municipal governments. It is the influence of politics which prevents the enforcement of the laws which exist for our protection. Politics and greed are synonymous terms. Sanitation and the preven. tion of disease and of death are disregarded if the enforcement of the law should interefere with the official life, pleasures and emoluments of the politician.

Politics in this country not only limits the enforcement of sanitary measures, but politics has had a blighting influence upon the advancement of medical education. We have no law governing the conduct of medical schools or fixing a uniform standard of requirements for graduation, before beginning the practice of medicine. Each State has its own medical law, and no two have like laws. But few place the standard of requirements high, and most of them have very minor requirements. In many States a charter for a medical school may be obtained for a small fee by any body of men who may please to originate a diploma factory. In this city alone are twenty or more medical schools. In this, as well as in some other municipal matters, Chicago leads the world. Other States and other cities boast of medical colleges galore. The most of these are private institutions owned partly or wholly by the teaching faculty. The expenses of the institution are paid from the fees derived from the students. The result in most cases is what one would expect. Students unfit to study medicine are admitted to the schools, while inadequate facilities for teaching prevent the proper and thorough education of the student. He goes forth with a diploma, which is equivalent to a license to practice in most States, for in but a few States is an examination to obtain a license necessary. Thus, the profession is crowded with physicians who are not prepared for the work they should do; the people suffer in consequence and scientific advancement is retarded thereby. Again, once a license is obtained, the State authorities are in most instances powerless to annul it, even if the holder thereof viciously prostitute his practice. In practice the law says all physicians are equal who hold a license to practice. The one may strive by all honest means to conscientiously help suffering humanity; the other may be a fiend on earth. Murder and lesser sins may thus be lawfully committed. The criminal may write the death certificate which affords safe burial of the victim. All medical practitioners are, however, injured and their influence for good is lessened by every evil-doer in medicine. Comment is unnecessary. The influence of politics has more to do than any other one factor in the retardation of medical progress and in limiting the possibilities of medicine.

Science is gradually and surely overcoming this evil. In some States excellent laws have been estab. lished, requiring schools to admit only students who are properly prepared to study medicine. The curri. culum must contain certain branches and the course of study must extend over four years. State examinations are also required for a license to practice, to which the applicant for examination is eligible only upon the evidence that he has taken a college medical course extending over a period of four years. All of the States will eventually be forced into the plan, not by law but by the people, who are slowly awakening to a better knowledge of things medical. Our State, county and city medical institutions are usually misgoverned by politics, and the patient and scientific medicine suffer in consequence. The use of anatomic material is so restricted by law in some States that medical education suffers. It is only since 1885 -twelve years - that anatomic study has been untrammeled in Illinois. It will surprise many of you to know that previous to 1874 the law of this State made no provision for the use of anatomic material, and at the same time made it a criminal offense to dissect or experiment surgically upon cadavers illegally obtained.

Vivisection has been a means of research which has so enriched our knowledge of physiology, has so perfected operations in surgery and so broadened our knowledge of pathology that thousands of human lives have been saved. Nevertheless, antivivisectionists have secured the adoption of laws in some countries, and in some States so restricted vivisection as to retard medical progress. The charge of cruelty to animals without material addition to our knowledge is not borne out by fact. No scientist worthy of the name is cruel. No scientist desires or asks for unrestricted and general vivisection. By authorized teachers and honest searchers after truth, no cruelty will be practiced. The knowledge gained will, in the vast future, be the means of saving the lives and relieving the sufferings of many times more human beings than the number of animals sacrificed. In the meantime the antivivisectionists will perform a real service and save much brute suffering if they will turn their attention and influence to the relief of the overworked, underfed beasts of burden which drag overloaded drays, tramcars, and carrettes about the streets, and the time they may spend in protection of our birds from the plume hunter will not be lost.

Our knowledge of pathology has been enormously increased in the last few years. The cause of disease is very much better understood. There is now no longer a reason for the existence of the many theories of medicine of former years. The scientific physician whose knowledge of anatomy, chemistry, general biology, pathology and clinical medicine is ripe, will therefore recognize the disease and its cause, if it is known. In the attempt to relieve the individual he will use every endeavor to remove the cause or to neutralize it. He will use anything and everything which his knowledge and judgment dictate for the relief of the patient. Pathies do not exist for him. A liberal and exact education in the foundation studies of medicine, teaches him to take a broad-minded view of all things pertaining to medicine. The adoption of a theory with a pathy attached necessarily includes belief in and practice of a narrow dogma. Recovery of the acutely ill, is frequent enough under all sorts of management to afford argument of a specific cure-all. The man who practices a pathy burrows in a ditch; his horizon of observation becomes narrower as he digs. The existence of pathies is an. obstruction to medical progress. To-day there is no reason for the existence of the word "pathy." The properly educated man can no longer ignore the existence of disease and treat the symptoms only. He cannot affirm that only vegetable medicines should be used and that all metallic medicines are poisonous. He can not affirm that water alone should be used and that it may always be applied without danger. He knows that manipulations alone can not remove a disease. He knows that electricity is not understood therapeutically, and ascribes much of its value to its moral effect. $\mathrm{He}$ recognizes the fact that certain conditions of the mind 
and body are relieved by hypnosis and by hypnotic suggestion, whether it be induced by the incantations of the Indian medicine man, the Buddhist and the black man of Africa; by the laying-on of hands of the mesmerist and faith healer, or by the prayer of the Christian scientist. He may be willing to use any or all of these methods, in the proper and few instances in which they may be indicated. I will not say that the average physician who possesses all the qualifications of a scientific man will try to induce a cure by the laying-on of hands or by prayer. $\mathrm{He}$ would probably think that equally good or better effects would be produced by a good dose of calomel.

In the United States but little scientific medical work is done under National or State expense and control. The medical department of the regular army encourages the medical officers to make scientific investigations, and furnishes the necessary apparatus for such research. A few medical officers of the army have distinguished themselves by excellent scientific medical work.

The navy has not recognized its medical officers by proper rank, nor has it encouraged or even given opportunity for scientific medical investigation. The marine-hospital service is composed of excellent medical men. Upon this department has devolved most of the National sanitary work of the last few years. Its powers and possibilities are, however, limited.

A few States have universities with medical departments, and in some of them excellent biologic and chemic work is done at the expense of the State. Most of the States have boards of health, some of them composed of excellent medical men, clothed with sufficient power to be of benefit to the people. The boards of health of many other States are usually composed of medical men selected for political reasons. With every change of the political party in power, the members of the board, whether good or bad, are also changed. The boards of health of many of the States have done excellent anitary work. Many have done much also to rid the medical profession of unqualified men, and in a measure, to elevate the standard of med. ical education, by recognizing the diplomas of only those medical schools that fulfilled the requirements of the boards in reference to the medical curriculum and time of study. The full usefulness, however, of the State boards of health, of the teachers in the State universities, and of the medical officers of the army, the navy, and of the marine-hospital service is prevented by political and commercial interests, or by environment inimical to scientific work. The greater part of the real scientific work in medicine in this country is done by individuals working privately at their own expense, or by teachers in institutions supported by the contributions of private citizens. Most of the good scientific medical workers are poor, and are obliged to earn a living by professional practice, a time-consuming impediment to proper scientific investigation. A mind full of anxiety, burdened with the responsibility of a life threatened by disease, is not as clear or as capable of unraveling the problems of medical science as that of the man whose whole time may be given to a special line of research.

In many foreign countries the governments recognize the scientific workers by paying them living salaries and by providing apparatus and opportunity for special lines of investigation. In this country the government maintains an agricultural department for the protection of the products of the farm, and an interstate commerce commission for the purpose of regulating and equalizing the interchange of the commodities of the States. This is done for commercial reasons. There is a commissioner of pensions-the agent of the government in the financial interests of the soldier. There is reason and justice in the maintenance of these departments. But there is just as much, if not more, reason, for the existence of a National Commission of Health-a commission with power to regulate the sanitary problems of the country and to adjust matters medical between the States as fully and definitely as the interstate commerce commission performs its duties.

In law a human life is worth $\$ 5000$ to the State. Why should the National government and the State not establish laboratories, or support those already established by private institutions, for the purpose of discovering the means of saving human life? Commercially a human life is worth more than an ox or a horse, and yet the government is more watchful of the health of animals which go to the slaughterhouse, or of the possible contamination of the farms by Canadian thistles, or by an invasion of grasshoppers, than of its citizens. The probable explanation is that corn, wheat and animals have an immediate visible commercial value $\theta_{\xi}$ while a human life is the principal which earns only a small visible annual interest.

The limitations of medicine in the management of acute infections and contagious diseases has always been great. The success in the prevention of these diseases has been greater than in the healing of those already sick. The discovery of bacteria and the relation they bear to the infectious and contagious diseases has afforded a still better means of prophylaxis and made a more rational treatment possible. We have looked upon these diseases as self-limited in duration-self-limited to accord with the life cycle of the invading germ. The materia medica does not furnish us a drug which will cut short the disease. The drug strong enough to kill the invading germ is equally deadly to the host. We modify the course of the disease only. We attempt to carry the patient through the illness by hygienic measures, simple food, bathing to modify fever, and by measures to support the patient until the invading army shall disappear. Specific medication is of no value except in the malarial diseases and in syphilis. This limitation of medicine is pronounced. But the microscope and chemistry have discovered a principle which has already worked wonders in the cure of some of the infectious diseases-a principle which appears to be applicable to many if not all of the diseases due to bacteria. It seems that bacteria not only secrete a poison which is the agent producing the symptoms of the patient, but that, like man, the germs are the source of their own undoing, for they also secrete or excrete or manufacture a substance which deals death to themselves and may also neutralize the disease-producing poison in the patient. The chemist has been able to isolate the toxin and the antitoxin in a few diseases. Furthermore, it has been found that an individual treated with the antitoxin, not only more certainly recovers from a particular infection, but that a well individual treated with the antitoxin may be protected for a longer or shorter time from bacterial invasion, or at least from the disease-producing toxin. The accidental discovery by Jenner of the relation of cowpox to smallpox, and the resulting protection against 
smallpox by bovine vaccination; the further discov- studies-chemistry, physiology, general biology, aneries of Pasteur, of the possibilities of immunization atomy, pathology, pharmacology and materia medica of animals by inoculation with the attenuated virus - will either be completed or the principles thereof of a disease, and the final brilliant discovery of, and will be mastered in the first two years of medical the possibility of the utilization of, the respective study. Then must come the application of the knowlantitoxins in the cure of, and in the prevention of, edge possessed of the foundation branches to the some of the infectious diseases, establishes a principle study of disease in the living and the dead. In hoswhich is so important as to eclipse almost any other pitals and dispensaries, in chemic and pathologic event in medical history. The brilliant results ob laboratories, must the student labor to recognize distained in that dreaded disease, diphtheria, alone, from ease by the phenomena termed symptoms, physical the application of this principle, is enough to fix it as signs, and by the changes which occur in the tissues, a truth and justify us in the hope that it may be suc- the blood, and the various secretions and excretions cessfully applied in the near future to many other of the body in disease.

infectious diseases. In that branch of medicine classed as surgery, bacteriology made possible a knowledge of true cleanliness which has enabled the surgeon to invade with impunity, every part of the human body. Hence the horizon of surgery is wide and its limitations now are few.

I have said that many of the present limitations of medicine will disappear in the future. By what means may we hope to remove the obstructions to medical success? We can help to modify, and perhaps in the future hope to see the disappearance of, the abuses of medicine due to politics. We should exert ourselves to influence the establishment of a non-political, National Commission of Health, with power to regulate the study and the practice of medicine by a uniform law in all the States; with power to command the civil officers of the States in the enforcement of sanitation in relation to the contamination of food and drink, in the dissemination of contagious disease, etc. We should try to influence the government, both National and State, to recognize the scientific workers in medicine and the allied sci. ences by offering inducements in the way of honors and money reward for the discovery of facts which are of use in prolonging life and palliating suffering. student who enters the field of medicine should be so thoroughly prepared, should have the proper facilities for study, and should give such time to the study of the fundamental branches and of the principles of medicine that he may command every possible means of prolonging life and relieving suffering. So prepared, he will embrace no dogma and recognize no pathy. A physician, he will command the respect and love of the people, who will listen to and heed his advice and instruction. Every physician so educated will exert a wide influence in helping to remove the conditions of the people which tend to limit the usefulness of medicine.

In closing, let me say a few words of the possibilities and the needs of this school. If we add to the great influence which this school possesses because of the reputation gained by fifty years of progressive improvement in medical work, the advantage which must result from the affiliation with the great University of Chicago, we may hope for the ideal in medical education. The broad-minded policy of the University will be admirably executed by the splendid mind of the man who conceived the plan. Over the whole Northwest are schools, academies and colleges that have shaped their courses of study to correspond with the curriculum of the University. Students will be piluted through the preparatory school. the academy, the college and the University, their minds moulded, trained and disciplined with a forethought of the final life-work of the individual. So prepared, a student will begin the study of medicine. The foundation

To accomplish ideal work in the last two or three years of a medical college course, it is necessary to have at hand a plentiful amount of material with which to work. Not only must the amount of material be sufficient, but it must be situated, in reference to facility of use, that all that is possible may be obtained from it. It is, therefore, necessary that proper buildings be had for both dispensary and hospital patients. The dispensary must be a clinical building, so arranged with rooms for clinical examination and for laboratory research, that all students may come in direct contact with the patient, and be enabled to make the examinations I have named above. A free-bed hospital should also be accessible, to furnish examples of the acute and severer forms of dis. ease, with laboratories and apparatus for thorough examination of everything of which analysis is necessary, in the recognition of disease and in the study of the action of remedies used in the attempt to heal. Facilities should be afforded, in an annex or building closely adjacent to the hospital, for the study of morbid anatomy. Here, under the proper direction of a pathologist, the student should be enabled to carry on the more practical study of pathology, the principles of which he learned in his first two years of medical college work. Here he should be able to trace the relation of the morbid changes to the symptoms, to the physical signs and to the alteration of the secretions and excretions of the body, which he was able to observe in the wards of the hospital. By this means he will be able, not only to understand the principles of the various subjects of medicine, when separately considered, but also their intimate relationship to each other. It is not too much to hope that this institution shall in the near future have a clinical building with all of the modern conveniences which architecture can furnish, including laboratories, with every means which shall afford the surest recognition of disease, and thus give greater comfort and surer means of relief to the sick. It is absolutely necessary that this school shall have a free private hospital governed entirely by its faculty, with all of the laboratories for the recognition of disease, and the examination of the morbid changes which occur in the human body. With a clinical building, and with a hospital such as I have attempted to describe so briefly, this school, possessing as it does, the present means of obtaining students thoroughly fitted for the study of medicine, and with almost perfect facilities for the study of the fundamental branches of medicine, will soon attain an ideal medical course. With such an institution in the West, medical education will be so stimulated that other institutions, even though they have lesser facilities, will attempt to keep in line.

The medical man of the future will thus be, not 
only better prepared to meet, but will also be better equipped to further lessen the limitations of medicine.

100 State Street.

\section{ORIGINAL ARTICLES.}

\section{THE ESTIMATION OF URIC ACID IN URINE.}

Presented to the Section on Materia Medica, Pharmacy and Therapeutics, at the Forty-ninth Annual Meeting of the American Medical Association, held at Denver, Colo., June 7-10, 1898.

BY HENRY C. C. MAISCH, Рн.D. PHILADELPHIA, PA.

While connected with the Stetson Laboratory of Hygiene, my attention was called to the fact that it was desirable to make a study of the conditions under which there was an increased, and other cases in which there was a decreased, elimination of uric acid. Intimately associated with this would be a physiologic study of tissues and probubly also cell metabolism; in other words, determining the place occupied by uric acid in the chemistry of the animal body. The purely physiologic study being out of my line, I determined, on the recommendation of two of my former col. leagues, Dr. Judson Daland and Dr. Frank Massey, to take up the purely chemic side of the question.

The first step in the investigation would be to determine on a method for the estimation of uric acid which would be comparatively simple in its application, and which would in the different operations be accompanied with the fewest sources of error. In looking over the literature on the subject we found many contradictory statements as to the accuracy of one and the same method. It is possible that a methou under certain conditions will give accurate or fairly accurate resulte, while in other cases the same process will give results which vary considerably from the truth. It ie not absolutely necessary for our purpose to study the cause of variation, but an examinaiion of the methods under various conditions would be sufficient. and from the data thus obtained determine on a method which would be used in the principal investigation.

It would seem fairly simple to determine on an accurate method by taking the simplest case possible and trying the different processes on this one. I refer here to muking a standard solution of uric acid of known purity and applying the different tests. But from the very start we have to contend with the ready decomposition of uric acid while in solution. It is a well-known fact that uric acid in an alkaline liquid is more or less rapidly decomposed into a number of distinct compounds which form at the end carbon dioxid, ammonia and oxalic acid. This decomposition is due to oxidation and hydration on the addition of oxygen and hydrogen in the form of water, $\mathrm{H}_{2} \mathrm{O}$, to the molecule of uric acid, $\mathrm{C}_{5} \mathrm{H}_{4} \mathrm{~N}_{4} \mathrm{O}_{3}$. A similar change takes place also in urine when exposed to the air with. out sterilization or preservation in some manner or other. It is necessary, therefore, that a urine should be examined for uric acid as soon as possible after voidance.

The results obtained in estimating the amount of uric acid in a simple solution of uric acid can not be taken as applying with like force to the estimation in urine, as I will show later on. The difference is due very likely in the organic and inorganic compounds found in the urine, which among other properties show a peculiar solvent action toward the urates, this peculiar behavior residing principally in the phos. phates and the urea.

In estimating uric acid in a sample of urine it is decidedly preferable to use that passed in twenty-four hours, as this alone will give a criterion as to quantity and assist very materially in computing the results obtained. It is possible that when the urine usually passed is rather concentrated under the influence of alcoholic beverages, the quantity of water excreted is materially increased, the urine becomes diluted, and if a sample of this latter urine is used the proportion of uric acid is diminished.

For the work in hand it was necessary to apply the tests to the same urine throughout, but it being impossible to obtain the necessary quantity from one person at one time, it was thought best to collect a lot of urine from different persons and then make the estimations on the collective urine. I therefore sent. a large vessel to one of the departments of the J. B. Stetson hat factory, and had it filled without paying any attention as to whether persons using the same were in health or under treatment for any disease. The quantity obtained amounted to about four gallons, and was furnished by eighty persons.

The urine showed the specific gravity of 1.021 , and contained neither sugar nor albumin. Before taking the quantity for each estimation the urine was thoroughly mixed each time. In reporting on the different methods I will begin with the one first recom. mended, and which to all appearances would be the simplest, taking into consideration the slight solubility of the uric acid. From this I will continue through the other methods applied, becoming gradually more difficult in application, and ending with the process which I have adopted as being the one which unites, accuracy and ready applicability.

The first method wo would have to consider is that of Heintz, in which the uric acid is set free by means of hydrochloric or other acid, and after standing for at least forty-eight hours, collecting the precipitated uric acid and weighing. When applying the rules as they pertain to ordinary solutions it would be expected that only a small quantity of hydrochloric acid would be necessary to complete the precipitation. It has, however, been shown that a solution of urea has a solvent action on uric acid, probably forming therewith a chemic compound which, however, is not solu. ble in a highly acid medium. It is, therefore, usual to add 20 c.c. of strong hydrochloric acid to 100 c.c. urine, which is a considerable excess, but even with this excess a complete precipitation does not take place, uric acid being soluble in water in the proportion of 1 to 16000 . According to this the correction would only be slight, and it is given as $0.0038 \mathrm{gm}$. for each 100 c.c. of liquid in use. Salkowski found that after treating 200 c.c. of urine as above, he could still isolate from the filtrate thus obtained from 0.044 to $0.07 \mathrm{gm}$. of uric acid by supersaturating with ammonia and precipitating with ammoniac silver nitrate solution. I applied this test with hydrochloric acid and also with acetic acid, and found

With $\mathrm{HCl}, 1, .0353 ; 2, .0349 ; 3, .0369$-mean 0.0357 per cent. With $\mathrm{C}_{2} \mathrm{H}_{5} \mathrm{O}_{2}, 1, .0338 ; 2, .0375 ; 3, .0407$-mean 0.0373 per cent.

What surprised me somewhat was that I obtained with the acetic acid macroscopic crystals of uric acid which at first were perfectly transparent and of a reddish color, but on drying became opaque. 